\title{
Estradiol Mediates Fluctuation in Hippocampal Synapse Density during the Estrous Cycle in the Adult Rat
}

\author{
Catherine S. Woolley and Bruce S. McEwen \\ Laboratory of Neuroendocrinology, Rockefeller University, New York, New York 10021
}

\begin{abstract}
We have found that the density of synapses in the stratum radiatum of the hippocampal CA1 region in the adult female rat is sensitive to estradiol manipulation and fluctuates naturally as the levels of ovarian steroids vary during the $\mathbf{5} \mathbf{d}$ estrous cycle. In both cases, low levels of estradiol are correlated with lower synapse density, while high estradiol levels are correlated with a higher density of synapses. These synaptic changes occur very rapidly in that within approximately $24 \mathrm{hr}$ between the proestrus and estrus stages of the estrous cycle, we observe a $32 \%$ decrease in the density of hippocampal synapses. Synapse density then appears to cycle back to proestrus values over a period of several days. To our knowledge, this is the first demonstration of such short-term steroid-mediated synaptic plasticity occurring naturally in the adult mammalian brain.
\end{abstract}

Plasticity in the adult nervous system has historically been thought to result from changes in the physiology and/or biochemistry of neuronal circuitry, the physical structure of which has been established during early development (for review, scc Arnold and Breedlove, 1985; Gould et al., 1991). Recent evidence, however, has indicated that adult neuronal circuits are much more structurally plastic than previously thought. Several laboratories have observed naturally occurring morphologic changes in the dendrites of adult neurons that suggest ongoing modification in patterns of synaptic communication between these cells and their afferents (Meyer et al., 1978; Brandon and Coss, 1982; Burgess and Coss, 1983; Purves et al., 1986; Forger and Breedlove, 1987; Woolley et al., 1990). In this report, we present direct evidence for such synaptic plasticity in that we demonstrate naturally occurring, steroid-mediated fluctuation in the density of synapses on hippocampal pyramidal neurons in the adult mammalian brain.

Our laboratory has recently shown that, in the adult female rat, the density of apical dendritic spines on CAl hippocampal pyramidal neurons is positively correlated with circulating levels of estradiol and progesterone. We first observed changes in dendritic spine density with experimental manipulation of these hormones (Gould et al., 1990), and subsequently at different stages of the $5 \mathrm{~d}$ estrous cycle when estradiol and progesterone

Received Aug. 19, 1991; revised Jan. 23, 1992; accepted Jan. 28, 1992.

This work was supported by NS 07080, NRSA Training Grant GM07524-14, and the Richard Lounsberry Foundation. Special thanks to Dr. Barbara McGuire for expert advice and to Helen Shio for excellent technical assistance.

Correspondence should be addressed to Catherine S. Woolley, Laboratory of Neuroendocrinology, Rockefeller University, 1230 York Avenue, New York, NY 10021.

Copyright (C) 1992 Society for Neuroscience $0270-6474 / 92 / 122549-06 \$ 05.00 / 0$ levels are naturally high or low (Woolley et al., 1990). As dendritic spines are the sites of the majority of excitatory input to hippocampal pyramidal neurons (Westrum and Blackstad, 1962; Harris and Stevens, 1989), the implication of these findings is that the density of synaptic contacts between hippocampal pyramidal neurons and their excitatory afferents is also under the control of estradiol and/or progesterone. Further, the short-term variations in circulating levels of these ovarian steroids that occur during the estrous cycle may result in ongoing, cyclic fluctuation in synaptic connectivity between pyramidal cells and their afferents.

In order to investigate these possibilities, we have made statistical estimates of synapse density in the stratum radiatum of the hippocampal CA1 region in adult female rats both with experimental manipulation of estradiol levels and as estradiol levels drop naturally in the shift from the proestrus to the estrus phase of the estrous cycle. In two experiments, synapse density in ovariectomized rats treated with either estradiol or oil vehicle was evaluated using, in the first case, a "conventional" estimation procedure based upon large numbers of randomly taken, area-weighted micrographs (Beaulieu and Colonnier, 1985) or, in the second case, the Disector method (Sterio, 1984; DeGroot and Bierman, 1986). The "conventional" estimation procedures are generally considered to be inferior to the Disector method (DeGroot and Bierman, 1986; but see Calverley et al., 1988) because the "conventional" techniques rely on the assumption that synaptic junctions are circular, disk-shaped structures, which they almost certainly are not (Harris and Stevens, 1989). The Disector method, on the other hand, is unbiased by the size, shape, or orientation of the test objects, in this case synapses, under study. Because we found the same relationship between treatment groups using either method and because of the general superiority of the Disector method, only the Disector was used for the estrous cycle experiment. In this third case, we compared synapse density in rats in the proestrus phase of their estrous cycle, in which estradiol levels are highest, to synapse density in rats in the estrus phase of the cycle, in which estradiol levels are lowest (Smith et al., 1975). In the experiments in which the Disector method was used, the left half of the brain was processed for electron microscopy while the right half was processed for light level analysis of dendritic spine density on CA1 pyramidal cells.

\section{Materials and Methods}

\section{Animal treatments}

A total of 22 adult female Sprague-Dawley rats $(275 \mathrm{gm})$ were used in this study. These rats were group housed with unlimited access to food and water.

For the experiments with experimental manipulation of estradiol lev- 
els, rats were ovariectomized under Metofane anesthesia. Three days following surgery, half of the rats received two injections of $10 \mu \mathrm{g}$ of estradiol benzoate in $100 \mu \mathrm{l}$ of sesame oil $24 \mathrm{hr}$ apart. The other half of the rats received injections of oil vehicle at these times. Forty-eight hours after the second injection, the rats were deeply anesthetized with Nembutal and transcardially perfused with $2 \%$ paraformaldehyde, $2 \%$ glutaraldehyde in $0.1 \mathrm{M}$ phosphate buffer ( $\mathrm{pH} 7.4)$. The heads of these animals were postfixed overnight at $4^{\circ} \mathrm{C}$ in the perfusate solution. Brains were then removed from the cranial cavities and blocked to contain the rostral hippocampus.

For the estrous cycle experiment, daily vaginal smears were taken for over 2 weeks and only those animals with regular $5 \mathrm{~d}$ cycles were used. In the late afternoon (1-2 hr before "lights off") of either the proestrus or the estrus phase of the estrous cycle, these rats were deeply anesthetized with Nembutal and transcardially perfused as described above.

\section{Histology}

For electron microscopy, 250- $\mu$ m-thick coronal sections were cut through the rostral hippocampus using a Vibratome. Sections corresponding to Paxinos and Watson (1986) plates 31-33 were fixed in osmium tetroxide en bloc and stained with uranyl acetate, dehydrated in graded ethanols, and flat embedded between plastic coverslips in EMBED-812. Blocks were trimmed to contain only the apex of the CAl pyramidal cell layer, from the stratum oriens to the stratum lacunosum-moleculare. Semithin sections were cut, stained for Nissl with toluidine blue, and drawn at $250 \times$ using a camcra lucida drawing tube. These drawings were used for orientation on ultrathin sections during data collection. Ultrathin sections were stained with uranyl acetate and lead citrate.

For experiments using the Disector method, the left half of the brain was processed for electron miscroscopy and the right half was processed according to a modified version of the single-section Golgi impregnation technique. Briefly, $100-\mu \mathrm{m}$-thick coronal sections through the rostral hippocampus were cut into a bath of $3 \%$ potassium dichromate in distilled water using a Vibratome. These sections were then incubated overnight at room temperature in $3 \%$ potassium dichromate, rinsed in distilled water, and mounted onto ungelatinized slides. A coverslip was then glued over the sections at the four corners of the slide. These slide assemblies were incubated in $1.5 \%$ silver nitrate in distilled water overnight in the dark. Following this, sections were rinsed in distilled water, dehydrated in graded ethanols, cleared in AmeriClear, and coverslipped.

\section{Data analysis}

All grids containing ultrathin sections were coded prior to quantitative analysis, and the code was not broken until the analysis was complete.

"Conventional" estimation procedure. Estimation of synapse density using a "conventional" method (Beaulieu and Colonnier, 1985) was performed as follows. (1) From each of two blocks of tissue for each brain, 20 electron micrographs were taken randomly from a region in the stratum radiatum between 300 and $500 \mu \mathrm{m}$ from the pyramidal cell layer; these micrographs covered an area of approximately $3500 \mu \mathrm{m}^{2}$ per brain. (2) The number of synapses $(N)$, defined as having both a postsynaptic density and at least two vesicles in the presynaptic terminal no more than $0.2 \mu \mathrm{m}$ from the synaptic cleft, was counted. (Note that these requirements leave some synapses undetected depending upon their orientation to the cutting plane. Thus, the values reported using this method likely underestimate the actual density of synapses in this region.) Without viewing serial sections, perforated synaptic junctions transected by the cutting plane usually appear as more than one synapse. In our analysis, when a single presynaptic terminal was associated with more than one postsynaptic density on the same postsynaptic element, it was counted as a single synapse. If, however, a presynaptic terminal clearly formed synapses with more than one postsynaptic element, then this was counted as more than one synapse. Additionally, synapses on dendritic spines were counted separately from those on dendritic shafts. Since relatively few cross sections contained a spine neck or spine apparatus, spines were defined as postsynaptic processes smaller than 2 $\mu \mathrm{m}^{2}$, lacking mitochondria. (3) The exact area of the sampled neuropil was measured using the Southern Micro Instruments (SMI) image analysis morphometry program. In order to normalize the sampled neuropil area that could contain synapses by excluding areas covered by large synapse-free structures, the areas of any cell bodies, myelinated processes, and dendritic processes greater than $2 \mu \mathrm{m}^{2}$ were measured using the SMI morphometry program and the sum was subtracted from the total area sampled to give a corrected value for the area sampled (corr
A). Subtraction of the areas of dendritic processes greater than $2 \mu \mathrm{m}^{2}$ has been determined by Harris et al. (1989) to achieve homogeneity of variance of cross-sectional areas of dendritic processes in the neuropil of stratum radiatum in the hippocampal CA1 region. (4) The length of each synapse transect was measured with the SMI morphometry system, and a mean was calculated $(\bar{d})$. (5) Estimated synapse density (est $N_{v}$ ) was then calculated:

$$
\text { est } N_{v}=(N / \operatorname{corr} A) \times \bar{d} \text {. }
$$

Disector procedure. Synapse density was estimated by the Disector method as follows (see DeGroot and Beirman, 1986, for details). (1) From each brain, six overlapping electron micrographs of three separate regions (18 micrographs per section) within the stratum radiatum between 300 and $500 \mu \mathrm{m}$ from the pyramidal cell layer were taken to create three "reference" planes. Regions containing cell bodies or blood vessels were intentionally avoided. The exact areas of the regions examined $\left(A_{i}, i=1,2,3\right)$, approximately $400 \mu \mathrm{m}^{2}$, were measured with the SMI morphometry program. (2) Micrographs of exactly the same regions were taken on an adjacent section to create three "look up" planes each necessarily of area $A_{i}$. (3) The number of synaptic transects contained in a "reference" plane but absent in the corresponding "look up" plane $\left(Q_{i}^{-}\right)$was counted in order to determine the number of synapses present within the volume defined by the "reference" plane, the "look up" plane, and the distance between them ( $h_{i}$; see below). As described for the "conventional" procedure, perforated synaptic junctions were treated as single synapses (this treatment could usually be substantiated by viewing the small series of adjacent sections taken for Disector analysis) and synapses on dendritic spines were counted separately from those on shafts. In order to double the efficiency of estimation, the analysis was performed treating each "reference" plane as a "look up" plane and vice versa. (4) Section thickness, which is equivalent to the distance between the "reference" and "look up" planes $\left(h_{i}\right)$ was determined by the method of Small (1968). (5) Estimated synapse density (est $N_{v}$ ) was then calculated:

$$
\text { est } N_{v}=\frac{\sum Q_{i}^{-}}{\sum A_{i} \times h_{i}} \text {. }
$$

Spine density analysis. Light level analysis of dendritic spine density on Golgi-impregnated CAl pyramidal cells was performed as follows. All slides containing Golgi-impregnated tissue were coded prior to analysis, and the code was not broken until the analysis was complete. In order to be selected for analysis, dendritic segments had to (1) be located between 300 and $500 \mu \mathrm{m}$ from the pyramidal cell layer in the stratum radiatum, (2) belong to a thoroughly impregnated neuron, (3) remain approximately in one plane of focus, and (4) be greater than $10 \mu \mathrm{m}$ in length. Appropriate segments were drawn using a camera lucida drawing tube. The number of dendritic spines visible along each segment was counted at $1250 \times$. The length of each dendritic segment was then determined from the camera lucida drawings using the SMI morphometry system, and data were expressed as number of spines per $10 \mu \mathrm{m}$ dendrite Five dendritic segments per cell and 10 cells per animal were analyzed in this way.

Means for each variable were calculated for each animal and the data were analyzed using unpaired, two-tailed $t$ tests.

\section{Results}

Qualitative examination at the light microscopic level of both Golgi-impregnated and Nissl-stained hippocampal tissue revealed no obvious differences either between estradiol-treated and control animals or animals in the proestrus versus estrus stage of the estrous cycle. Similarly, at the electron microscopic level, no qualitative differences were observed with hormone treatment or between estrous states.

On the other hand, quantitative electron microscopic analysis revealed a selective increase in the density of axospinous synapses in the stratum radiatum both with estradiol treatment and during proestrus when estradiol levels are naturally increased. Analysis using a "conventional" method to estimate hippocam- 
A

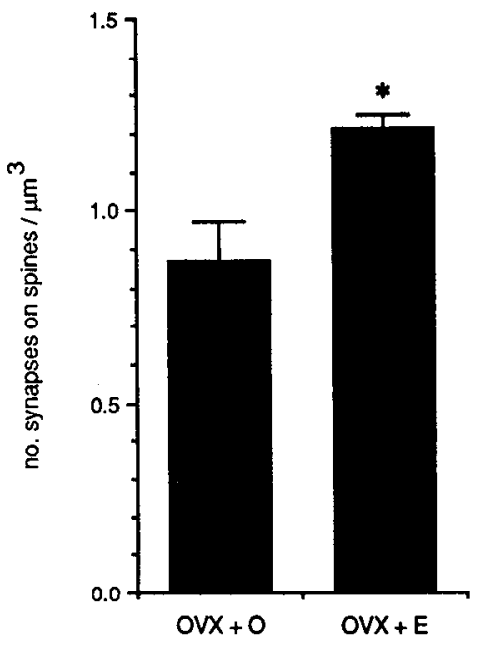

B

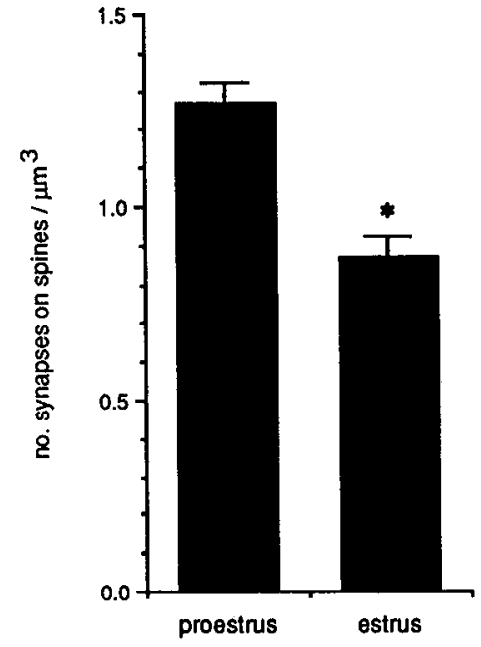

Figure 1. Estimated density of synapses on dendritic spines in the stratum radiatum of the CAl region of the hippocampus, in $A$, of an ovariectomized $(O V X)$ rat treated with oil $(O)$ or estradiol $(E)$ or, in $B$, of intact rats in the proestrus or estrus phase of the estrous cycle. Values represent means \pm SEM obtained using the Disector method. Note that in each case, higher estradiol levels are correlated with a greater density of synapses. Data were analyzed with unpaired, two-tailed $t$ tests, $n=4$ in each case. ${ }^{*}$, significant difference, in $A$, from $O V X+O$ or, in $B$, from proestrus, $p<0.025$. pal synapse density in ovariectomized rats revealed a $38 \%$ increase in the density of synapses on dendritic spines in estradioltreated compared to oil-treated animals $(T=2.175, p<0.05$; Table 1). On the other hand, estradiol did not appear to affect the density of synapses located on dendritic shafts $(p>0.1$; Table 1). Additionally, the mean length of synaptic transects of synapses made on dendritic spines was unchanged by estradiol treatment (mean $\pm \mathrm{SEM}$ ): OVX $+\mathrm{O}, 0.35 \pm 0.05 \mu \mathrm{m}$; OVX $+\mathrm{E}, 0.27 \perp 0.01 \mu \mathrm{m}(T=1.637, p>0.1)$. The results were similar for synapses made on dendritic shafts: OVX $+\mathrm{O}, 0.39$ $+0.04 \mu \mathrm{m} ; \mathrm{OVX}+\mathrm{F}, 0.36+0.05 \mu \mathrm{m}(T=0.347, p>0.5)$.

Analysis using the Disector method confirmed the selective increase in axospinous synapse density with estradiol treatment. Quantitative analysis of hippocampal synapse density in ovariectomized rats that received either estradiol or oil revealed a $28 \%$ increase in the density of synapses located on dendritic spines in estradiol-treated compared to oil-treated ovariectomized rats $(T=3.154, p<0.025$; Figs. $1 A$, 2; Table 2$)$. As with the "conventional" estimation procedure, estradiol did not appear to affect the density of synapses located on dendritic shafts estimated using the Disector method ( $p>0.1$; Table 2). Additionally, in agreement with our previously reported findings (Gould et al., 1990), estradiol treatment of ovariectomized rats resulted in a significant increase of approximately $35 \%$ in apical dendritic spine density on Golgi-impregnated CAl pyramidal cells $(T=4.567, p<0.02$; Table 2$)$.

When synapse density was analyzed in rats in the proestrus or estrus phase of the estrous cycle, the results were remarkably similar. Quantitative analysis using the Disector method to es-

Table 1. Density of synapses on dendritic spines or shafts obtained using a "conventional" method

\begin{tabular}{lll} 
Treatment & $\begin{array}{l}\text { No. synapses } \\
\text { on spines } / \mu \mathrm{m}^{3}\end{array}$ & $\begin{array}{l}\text { No. synapses } \\
\text { on shafts } / \mu \mathrm{m}^{3}\end{array}$ \\
\hline OVX $+\mathrm{O}$ & $0.56 \pm 0.02$ & $0.07 \pm 0.01$ \\
OVX + E & $0.90 \pm 0.16^{*}$ & $0.06 \pm 0.01$
\end{tabular}

Data are from the stratum radiatum of the CA1 region of the hippocampus in ovariectomized (OVX) adult female rats treated with either oil $(\mathrm{O})$ or estradiol (E). Values represent mean \pm SEM. Data were analyzed with unpaired, two-tailed $t$ tests, $n=3$ in each case.

* Significant difference from $\mathrm{OVX}+\mathrm{O}, p<0.05$. timate the density of hippocampal synapses in rats in the proestrus phase, when estradiol levels are highest, or the estrus phase, when estradiol levels are lowest, revealed a $32 \%$ decrease in the density of synapses on dendritic spines as estradiol levels drop in the transition from proestrus to estrus $(T=3.357, p<$ 0.02 ; Figs. $1 B, 3$; Table 2 ). In contrast, no change in the density of synapses on dendritic shafts was observed during the estrous cycle ( $p>0.1$; Table 2$)$. In parallel to these changes in synapse density and as previously reported (Woolley et al., 1990), apical dendritic spine density on Golgi-impregnated CA1 pyramidal cells decreased by approximately $23 \%$ between the proestrus and the estrus phases of the cycle $(T=3.412, p<0.02$; Table 2 ). In each of the three experiments, virtually all identified synapses that appeared to be on dendritic spines were asymmetric, while virtually all those observed on dendritic shafts were either clearly symmetric or not easily classified as belonging to either class. This relationship did not appear to be altered by estradiol treatment or during the estrous cycle.

\section{Discussion}

The results presented in this study demonstrate that differences in the density of dendritic spines on hippocampal pyramidal neurons that we have previously observed (Gould et al., 1990; Woolley et al., 1990) reflect an altered pattern of synaptic connectivity between these cells and their afferents. We have ob-

Table 2. Density of dendritic spines and density of synapses on dendritic spines or shafts using the Disector method

\begin{tabular}{lcll} 
Trcatment & $\begin{array}{l}\text { No. spines/ } \\
10 \mu \mathrm{m}\end{array}$ & $\begin{array}{l}\text { No. synapses } \\
\text { on spines } / \mu \mathrm{m}^{3}\end{array}$ & $\begin{array}{l}\text { No. synapses } \\
\text { on shafts } / \mu \mathrm{m}^{3}\end{array}$ \\
\hline OVX + O & $9.2 \pm 0.6$ & $0.87 \pm 0.10$ & $0.04 \pm 0.03$ \\
OVX + E & $14.1 \pm 0.8^{*}$ & $1.21 \pm 0.04^{*}$ & $0.06 \pm 0.03$ \\
Proestrus & $13.3 \pm 0.2$ & $1.27 \pm 0.05$ & $0.04 \pm 0.02$ \\
Fstrus & $10.2 \pm 0.5 \dagger$ & $0.87 \pm 0.05 \dagger$ & $0.05 \pm 0.02$
\end{tabular}

Data are from the stratum radiatum of the CA1 region of the hippocampus in ovariectomized (OVX) female rats treated with estradiol $(E)$ or oil $(\mathrm{O})$ or in intact adult female rats in the proestrus or estrus stage of the estrous cycle. Values represent means $\pm \mathrm{SEM}$. Data were analyzed with unpaired, two-tailed $t$ tests, $n$ $=4$ in each case

* Significant difference from $\mathrm{OVX}+\mathrm{O}, p<0.025$.

$\dagger$ Significant difference from proestrus, $p<0.02$. 

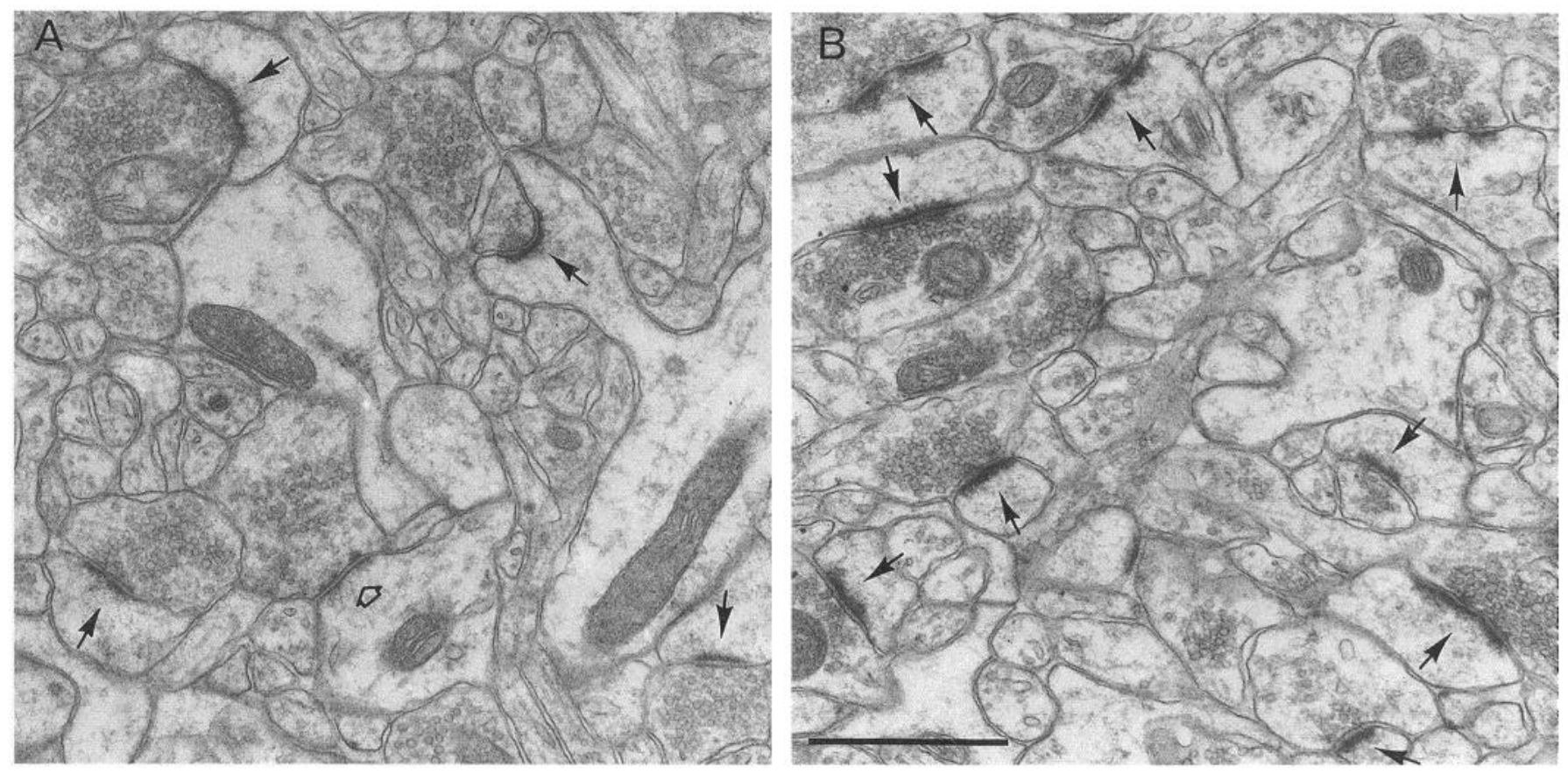

Figure 2. Electron micrographs of the stratum radiatum in the hippocampal CA1 region of an ovariectomized adult female rat that received oil $(A)$ or estradiol $(B)$. Synapses on dendritic spines are marked by solid arrows, whereas the open arrow in $A$ marks a synapse on a dendritic shaft. Scale bar, $1 \mu \mathrm{m}$.

served a fluctuation in the density of hippocampal synapses occurring during the estrous cycle in experimentally unmanipulated animals. While this fluctuation in synapse density could result from alterations in the levels of either gonadal or pituitary hormones, the fact that we observe such similar, short-term changes with estradiol manipulation strongly suggests that the differences in synapse density we have observed across the estrous cycle are mediated by estradiol.

Previous observations of gonadal steroid regulation of dendritic morphology have been made in sexually dimorphic nuclei that are involved in reproductive behavior (De Voogd and Nottebohm, 1981; Carrer and Aoki, 1982; De Voogd et al., 1985; Kurz et al., 1986; Forger and Breedlove, 1987; Miyakawa and Arai, 1987) or have been associated with the development of reproductive function (Meyer et al., 1978). Of these, the changes that occur naturally in the adult are seasonal (De Voogd et al., 1985; Forger and Breedlove, 1987) and thus take place over long periods of time. The steroid-mediated differences in synapse density we have observed are unique in that they occur naturally, over a period of as little as $24 \mathrm{hr}$, in a region of the adult mammalian brain that is not known to be sexually dimorphic or involved in reproductive function.

the changes in dendritic spine and synapse density that we have observed are most likely the result of changes in the number of dendritic spine/synaptic junction complexes present in the tissue as a function of hormonal state. While it is possible that treatment effects on synapse size or dendritic arborization could affect estimates of synaptic density without actually changing the number of spine/synapse complexes present, we have evidence that these factors are not responsible for the differences we have observed. First, with regard to synapse size, we found no difference in the mean length of synaptic transects with estradiol treatment; the difference in synapse density calculated with a "conventional" formula was clearly due to a greater number of synaptic profiles observed in estradiol-treated compared to control animals. Further, we observed very similar estradiol-mediated differences in synapse density using the Disector method, which is not biased by differences in the shape, size, or orientation of the test objects subjected to analysis (Sterio, 1984; DeGroot and Bierman, 1986). Second, it seems unlikely that estradiol is affecting dendritic arborization, as we have recently obtained evidence that parameters such as number of apical dendritic branch points and total apical dendritic length in CA1 pyramidal cells are not changed by estradiol treatment (C. S. Woolley and B. S. McEwen, unpublished observations). Thus, while it must be considered a possibility that a change in the volume of some component of the CA1 stratum radiatum could alter the total volume of this region, making differences in the density of synapses appear as a change in synapse number, it does not appear that an overall shrinking or extension of the pyramidal cell dendritic tree can account for estradiol-mediated changes in dendritic spine and synapse density.

We have observed changes in the density of axospinous synapses, but not in the density of contacts made on dendritic shafts. This, in combination with the fact that we observed very few asymmetric synapses on dendritic shafts in any treatment group, indicates that the decrease in the density of axospinous synapses reflects a loss of spine/synapse complexes with no concomitant increase in the number of synapses made on dendritic shafts. Thus, it appears that, in parallel with fluctuating estradiol levels, we are observing a fluctuation in the actual number of asymmetric synapses present rather than shifts in synapse location between spine and shaft. It is quite likely that transition states between dendritic spines with associated synapses and "empty" dendritic shaft regions exist, for example, presynaptic terminals lacking postsynaptic densities or vice versa. However, it is not possible to identify dendritic shaft regions positively as belonging to a spiny pyramidal neuron or to an aspiny hippocampal 

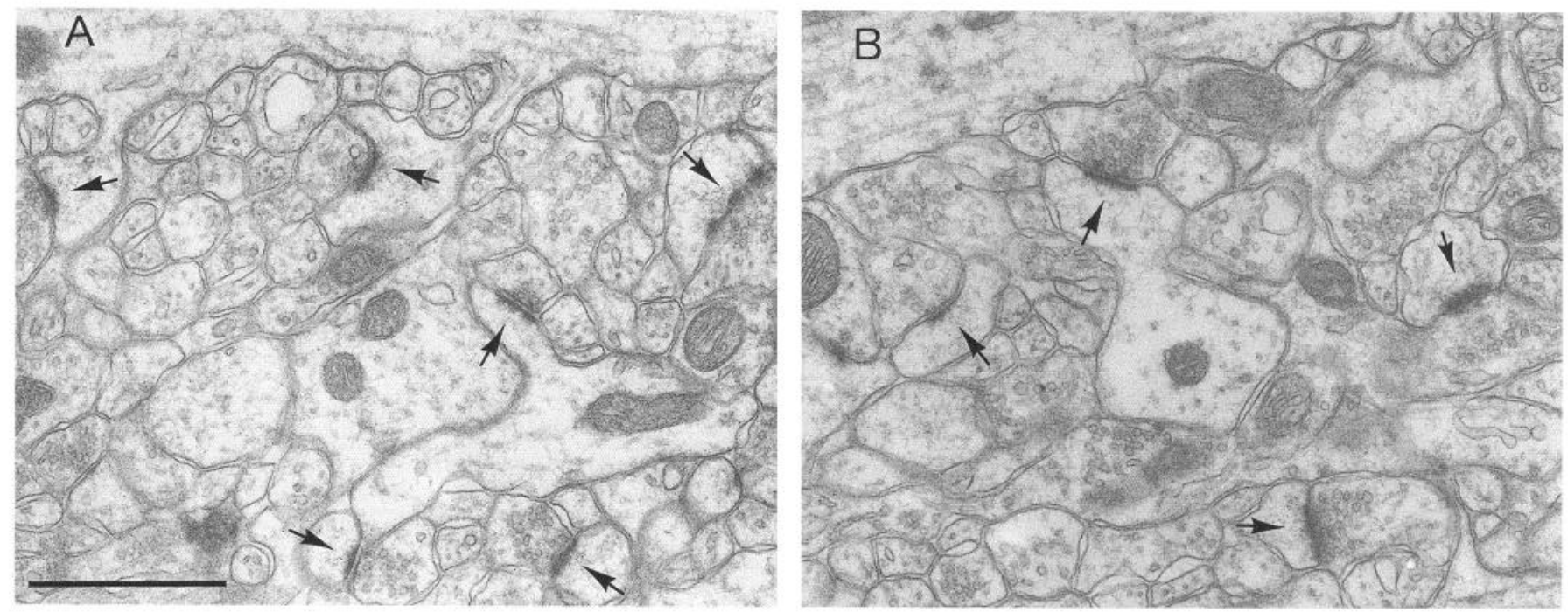

Figure 3. Electron micrographs of the stratum radiatum in the hippocampal CA1 region of an intact adult female rat in the proestrus (A) or estrus $(B)$ stage of the estrous cycle. Synapses on dendritic spines are marked by arrows. Scale bar, $1 \mu \mathrm{m}$.

interneuron without analyzing dendritic segments reconstructed from serial electron micrographs. Thus, a better understanding of the details concerning the changing relationship between preand postsynaptic elements on pyramidal neurons during fluctuations in dendritic spine and synapse density will depend on continuing studies using serial reconstruction to quantify such incomplete synapses under various hormonal conditions.

It is interesting to note that we did not observe degenerative profiles, either of an electron-lucent or dark variety (Fifkova, 1975), characteristically seen under pathological conditions such as denervation by experimentally induced lesions (Raisman and Matthews, 1972). While it remains a possibility that we might have observed some evidence of degeneration had we chosen other time points for analysis, we feel it is more likely that naturally occurring and reversible changes in connectivity that occur during the estrous cycle are distinct from the patterns of degeneration usually associated with damage.

The mechanism by which these reversible changes in neuronal morphology occur over a period of time as short as $24 \mathrm{hr}$ is unclear. It is possible that regulation of the density of synapses and dendritic spines is a direct effect of estradiol on CA1 pyramidal cells as a small population of these neurons accumulates ${ }^{3} \mathrm{H}$-estradiol (Loy et al., 1988), and a small population has been shown to be physiologically sensitive to estradiol in vitro (Teyler et al., 1980; Wong and Moss, 1991). However, because it is relatively few CA1 pyramidal cells that appear to be directly responsive to estradiol, it seems unlikely that the effects on spine and synapse density we have observed are due to effects of estradiol on CA1 pyramidal cells themselves. On the other hand, because dendritic spines and their associated synapses have been shown to depend on afferent connections (Parnavelas et al., 1974; Caceras and Steward, 1983; Steward and Visant, 1983; Benshalom and White, 1988), and CA1 pyramidal cells receive input from populations of neurons that are estradiol sensitive (Pfaff and Keiner, 1973; Bayer, 1985), it is also possible that differences in spine and synapse density are mediated indirectly by estradiol-sensitive CAl pyramidal cell afferents. Candidates for estradiol-sensitive inputs to CA1 pyramidal cells include neurons of the medial septum/diagonal band, entorhinal cortex, locus ceruleus, and raphe nuclei. The neuroanatomical basis for this hypothesis is currently being investigated in our laboratory. Another intriguing hypothesis is suggested by the recent finding of Blaustein et al. (1991) that estrogen receptors can be localized to axonal terminals in the guinea pig hypothalamus by combined electron microscopy/immunocytochemistry. It is not yet known whether a similar receptor distribution exists in the hippocampus of the rat. Although the possibility is highly speculative at this point, estrogen-sensitive terminals making synapses on dendritic spines of CA1 pyramidal cells could provide an anatomical basis for indirect, local action of estradiol in the regulation of dendritic spine and synapse density in this neural region.

As synapses located on dendritic spines are the sites of the majority of excitatory input to CA1 pyramidal neurons (Westrum and Blackstad, 1962; Harris and Stevens, 1989), our findings strongly suggest that activity of CA1 pyramidal cells could be modulated by circulating levels of estradiol. The fact that we have observed changes specifically in asymmetric synapses, which are presumably excitatory (Westrum and Blackstad, 1962; Andersen, 1987; Harris and Stevens, 1989), supports the possibility that CA1 pyramidal cell excitability could be increased when estradiol levels are high, at least in part, as a result of an increase in the density of excitatory inputs they receive. Our findings may help to explain previously reported effects of ovarian steroids on hippocampal pyramidal cell physiology in vivo that have correlated high levels of steroids with increased hippocampal neuronal activity both in the case of hormonal manipulation and during the estrous cycle (Terasawa and Timeras, 1968; Kawakami et al., 1970).

Furthermore, it seems likely that cognitive functions, which are undoubtedly dependent upon synaptic communication between neurons, would be affected by differences in synapse density and thus may be subject to fluctuations in hormone levels. The fact that we observe differences in hippocampal synapse density as great as $30 \%$ implies that normally occurring differences in the circulating level of estradiol might have important consequences for hippocampal function. As cognitive processes, particularly learning ability, known to involve the hippocampus (O'Keefe and Nadel, 1978; Olton, 1983; Squire, 1983), also appear to be influenced by estradiol both developmentally (Williams and Meck, 1991) and in the adult (Diaz-Veliz et al., 1989; 
Hampson, 1990), it is interesting to speculate on the possibility that estradiol could affect these processes, at least in part, through alterations in synapse density.

\section{References}

Andersen P (1987) Properties of hippocampal synapses of importance for integration and memory. In: Synaptic function (Edelman GM, Gall WE, Cowan WM, eds), pp 403-429. New York: Wiley.

Arnold AP, Breedlove SM (1985) Organizational and activational effects of sex steroids on brain and behavior: a reanalysis. Horm Behav 19:469-498.

Bayer SA (1985) The hippocampus. In: The rat nervous system (Paxinos G, ed), pp 335-352. Sydney: Academic.

Beaulieu C, Colonnier M (1985) A laminar analysis of the number of round-asymmetrical and flat-symmetrical synapses on spines, dendritic trunks, and cell bodies in area 17 of the cat. J Comp Neurol 231:180-189.

Benshalom G, White EL (1988) Dendritic spines are susceptible to structural alterations induced by degeneration of their presynaptic afferents. Brain Res 443:377-382.

Blaustein JD, Turcotte JC, Lehman MN (1991) Estrogen receptors in axon terminals in guinea pig hypothalamus: immunogold localization. Soc Neurosci Abstr 17:431.

Brandon JG, Coss RG (1982) Rapid dendritic spine shortening during one trial learning: the honeybee's first orientation flight. Brain Res 252:51-61.

Burgess JW, Coss RG (1983) Rapid effect of biologically relevant stimulation on tectal neurons: changes in dendritic spine morphology after nine minutes are retained for twenty-four hours. Brain Res 266: 217-223.

Caccras A, Steward O (1983) Dendritic reorganization in the dentate gyrus of the rat following entorhinal cortical lesions. A Golgi and electron microscopic analysis. J Comp Neurol 214:387-403.

Calverley RKS, Bedi KS, Jones DG (1988) Estimation of the numerical density of synapses in rat neocortex. Comparison of the 'disector' with an 'unfolding' method. J Neurosci Methods 23:195-205.

Carrer HF, Aoki A (1982) Ultrastructural changes in the hypothalamic ventromedial nucleus of ovariectomized rats after estrogen treatment. Brain Res 240:221-233.

DeGroot DMG, Bierman EPB (1986) A critical evaluation of methods for estimating the numerical density of synapses. J Neurosci Methods 18:79-101

De Voogd T, Nottebohm F (1981) Gonadal hormones induce dendritic growth in the adult avian brain. Science 214:202-204.

De Voogd T, Nixdorf B, Nottebohm F (1985) Synaptogenesis and changes in synaptic morphology related to acquisition of a new behavior. Brain Res 329:304-308.

Diaz-Veliz G, Soto V, Dussanbat N, Mora S (1989) Influence of the estrous cycle, ovariectomy and estradiol replacement upon the acquisition of conditioned avoidance responses in rats. Physiol Behav 46: $397-401$.

Fifkova E (1975) Two types of degeneration in the molecular layer of the dentate fascia following lesions of the entorhinal cortex. Brain Res 96:169-175.

Forger NG, Breedlove SM (1987) Seasonal variation in mammalian striated muscle mass and motoneuron morphology. J Neurobiol 18: $155-165$.

Gould E, Woolley CS, Frankfurt M, McEwen BS (1990) Gonadal steroids regulate dendritic spine density in hippocampal pyramidal cells in adulthood. J Neurosci 10:1286-1291.

Gould E, Woolley CS, McEwen BS (1991) The hippocampal formation: morphological changes induced by thyroid, gonadal and adrenal hormones. Psychoneuroendocrinology 16:69-86.

Hampson E (1990) Estrogen-related variations in human spatial and articulatory-motor skills. Psychoneuroendocrinology 15:97-111.

Harris KM, Stevens JK (1989) Dendritic spines of CAl pyramidal cells in the rat hippocampus: serial electron microscopy with reference to their biophysical characteristics. J Neurosci 9:2982-2987.

Harris KM, Jensen FE, Tsao B (1989) Ultrastructure, development, and plasticity of dendritic spine synapses in area CA1 of the rat hippocampus: extending our vision with serial electron microscopy and three dimensional analyses. In: The hippocampus-new vistas, Vol 52 (Chan-Palay V, Kohler C, eds), pp 33-52. New York: Liss.

Kawakami M, Terasawa E, Ibuki T (1970) Changes in multiple unit activity in the brain during the estrous cycle. Neuroendocrinology 6 : $30-48$.

Kurz EM, Sengelaub DR, Arnold AP (1986) Androgens regulate dendritic length in sexually dimorphic motor netirons in adulthood. Science 232:395-398.

Loy R, Gerlach JL, McEwen BS (1988) Autoradiographic localization of estradiol-binding neurons in the hippocampal formation and the entorhinal cortex. Dev Brain Res 39:245-251.

Meyer G, Ferres-Torres R, Mas M (1978) The effects of puberty and castration on hippocampal dendritic spines in mice. Brain Res 155: $108-112$.

Miyakawa M, Arai Y (1987) Synaptic plasticity to estrogen in the lateral septum of adult male and female rats. Brain Res 436:184-188.

O'Keefe J, Nadel L (1978) The hippocampus as a cognitive map. Oxford: Clarendon.

Olton DDS (1983) Memory functions and the hippocampus. In: The hippocampus (Seifert W, ed), pp 335-373. London: Academic.

Parnavelas JG, Lynch G, Brecha N (1974) Spine loss and regrowth in the hippocampus following deafferentation. Nature 248:71-73.

Paxinos G, Watson C (1986) The rat brain in stereotaxic coordinates, 2d ed. Sydney: Academic.

Pfaff DW, Keiner M (1973) Atlas of estradiol-concentrating cells in the central nervous system of the female rat. J Comp Neurol 151 : 121-158.

Purves D, Hadley RD, Voyvodic JT (1986) Dynamic changes in the dendritic geometry of individual neurons visualized over periods of up to three months in the superior cervical ganglion of living mice. J Neurosci 6:1051-1060.

Raisman G, Matthews MR (1972) Degeneration and regeneration of synapses. In: The structure and function of nervous tissue, Vol IV (Buorne GH, ed), pp 61-104. New York: Academic.

Small JV (1968) Measurement of section thickness. In: Proceedings of the fourth European Conference on Electron Microscopy, pp 609610. Rome: Tipographia Poliglotta Vaticana.

Smith MS, Freman ME, Neill JD (1975) The control of progesterone secretion during the estrous cycle in the rat: prolactin, gonadotropin and steroid levels associated with rescue of the corpus luteum and pseudopregnancy. Endocrinology 96:219-226.

Squire LR (1983) The hippocampus and the neuropsychology of memory. In: The hippocampus (Seifert W, ed), pp 491-511. London: Academic.

Sterio DC (1984) The unbiased estimation of number and sizes of particles using the disector. J Microsc 134:127-136.

Steward O, Vinsant SV (1983) The process of reinnervation in the dentate gyrus of the adult rat. A quantitative electron microscopic analysis of terminal proliferation and reactive synaptogenesis. J Comp Neurol 214:370-386.

Terasawa E, Timiras PS (1968) Electrical activity during the estrous cycle of the rat: cyclic changes in limbic structures. Endocrinology 83:207-216.

Teyler TJ, Vardaris RM, Lewis DL, Rawitch AB (1980) Gonadal steroids: effects on excitability of hippocampal pyramidal cells. Science 209:1017-1019.

Westrum LE, Blackstad TW (1962) An electron microscopic study of the stratum radiatum of the rat hippocampus (regio superior, CA1) with particular emphasis on synaptology. J Comp Neurol 119:281309.

Williams CL, Meck WH (1991) The organizational effects of gonadal steroids on sexually dimorphic spatial ability. Psychoneuroendocrinology 16:155-176.

Wong M, Moss RL (1991) Electrophysiological evidence for a rapid membrane action of the gonadal steroid, 17B-estradiol, on CA1 pyramidal neurons of the rat hippocampus. Brain Res 543:148-152.

Woolley CS, Gould F, Frankfurt M, McEwen BS (1990) Naturally occurring fluctuation in dendritic spine density on adult hippocampal pyramidal neurons. J Neurosci 10:4035-4039. 